\title{
A CONCORDÂNCIA VERBAL NO PORTUGUÊS EUROPEU: VARIAÇÃO E PREENCHIMENTO DO SUJEITO
}

\author{
Gislaine Aparecida de CARVALHO*
}

- RESUMO: Este artigo discute a correlação entre sujeito nulo e caráter forte da flexão verbal. À luz dos ensinamentos da Proposta Teórico-metodológica da Variação e Mudança Linguística, de linha laboviana, a análise da realização do sujeito no português europeu, em um corpus de língua falada, mostra que essa correlação existe, mas não é necessária: (i) há significativos percentuais de sujeitos preenchidos em estruturas, cuja morfologia verbal é suficientemente marcada para identificar a pessoa gramatical; (ii) a não concordância afeta negativamente o uso do sujeito nulo, notadamente com a forma pronominal a gente, cuja morfologia verbal apresenta, em algumas localidades do território português, três diferentes flexões: $1^{a}$ pessoa do plural, $3^{a}$ pessoa do singular e $3^{a}$ pessoa do plural. Além do expressivo índice de sujeitos preenchidos, há casos - ainda que não muito expressivos, mas não menos importantes - de não aplicação da regra de concordância com sujeitos antepostos, fato que contraria os contextos de variação previstos para o português europeu.

- PALAVRAS-CHAVE: Português europeu. Variação linguística. Sujeito preenchido. Sujeito nulo. Concordância verbal.

\section{Introdução}

Desde a tradição clássica, originada no mundo grego, reconhece-se a possibilidade de as línguas naturais permitirem que o sujeito esteja subentendido. Nas gramáticas de cunho normativo, o fenômeno do sujeito nulo aparece sob o rótulo mais geral de elipse, ou mais especificamente, como sujeito oculto: "[...] aquele que não está materialmente expresso na oração, mas pode ser identificado pela desinência verbal ou pela presença do sujeito em outra oração do mesmo período." (CUNHA, 1980, p.140, grifo nosso).

A variação sintática nas línguas naturais tem sido objeto de investigação em diferentes abordagens teóricas. Para a Teoria Gerativa, o foco inicial era determinar os Princípios invariantes que governavam as línguas, mas na década de oitenta a inserção do conceito de Parâmetro evidencia a preocupação com a diversidade sintática. Ao assumir como um dos seus pressupostos compatibilizar,

* UNEMAT - Universidade do Estado de Mato Grosso. Secretaria de Ciência e Tecnologia. Alto Araguaia - MT Brasil. 78780-000 - gislainemail26@yahoo.com.br 
de um lado, a hipótese de gramática universal inata, e de outro, a diversidade das línguas existentes, Chomsky $(1981,1982)$ desenvolveu aparato teórico para explicar a possibilidade de as línguas naturais permitirem que o sujeito esteja subentendido, fenômeno que remonta à tradição dos estudos gramaticais. Em sua Teoria de Princípios e Parâmetros, as línguas dividem-se em dois grandes grupos: as que exigem sujeito foneticamente realizado, denominadas [-] pro-drop, e as que permitem uma categoria vazia nessa posição, portanto [+] pro-drop (CHOMSKY, 1981).

Para os estudos de cunho normativista, o português brasileiro é língua de sujeito nulo, mas estudos empíricos divergem dos tradicionais: essa variedade "[...] convive com um sistema agonizante, em que ainda se refletem as características pro-drop, e um sistema em desenvolvimento, em que a riqueza funcional perdida já não permite a identificação de pro." (DUARTE, 1995, p.142).

Ao contrário do português brasileiro, a variedade europeia é considerada língua de sujeito nulo, quer pelos estudos normativistas, quer pela literatura de caráter linguístico-científico. Os dados de amostra de fala e escrita do português europeu obtidos por Duarte confirmaram uma gramática típica de língua [+] pro-drop (DUARTE, [2013?], 1995).

Pesquisas teóricas refinam o Parâmetro pro-drop e estudos empíricos descrevem quais fatores linguísticos e sociais estão mais diretamente associados à preferência ora pelo sujeito preenchido, ora pelo sujeito nulo. E é nessa última vertente que se inscreve este trabalho, cujo objetivo é atestar ou refutar o estatuto de língua de sujeito nulo homogeneamente atribuído ao português europeu.

Embora os estudos não sejam conclusivos, há uma tendência em associar a crescente preferência pelo sujeito preenchido no português brasileiro ao enfraquecimento da morfologia verbal (DUARTE, 1993, 1995). Portanto, a nossa hipótese é a de que no português europeu, que mantém um paradigma funcionalmente "rico", o sujeito nulo será a forma não marcada para essa língua ${ }^{1}$.

Para cotejar diferenças e/ou semelhanças entre o português europeu e o português brasileiro, a nossa análise, feita com base em amostras de fala de 10 localidades do território português, adotou os procedimentos teóricometodológicos da Variação e Mudança Linguísticas de linha laboviana, metodologia usada em muitas pesquisas que investigaram o mesmo fenômeno no português brasileiro (LIRA, 1982, 1988; BOTASSINI, 1998; CAVALCANTE, M., 2001; LAPERUTA, 2002; CARVALHO, 2005; BRAVIN DOS SANTOS, 2006).

Metodologicamente, assumimos a frequência de uso para distinguir uma forma linguística marcada de outra não marcada. Para os propósitos deste trabalho, a forma não marcada corresponderá ao sujeito nulo, dada sua maior frequência de uso. 


\section{A concordância verbal no português brasileiro e europeu}

Para a concordância sujeito-verbo, a expressão "o oposto do avesso" traduz a lendária assimetria entre o português europeu e o português brasileiro: neste, a concordância verbal chegou aos limites da simplificação (DUARTE, 1993; LOPES; MACHADO, 2005); naquele, mantém-se um conjunto de regras em causa categórica (GALVES, 1993, 2001; DUARTE, [2013?], 1993, 1995).

A flexão no português do Brasil não apresenta a oposição $1^{\mathrm{a}}, 2^{\mathrm{a}}$ e $3^{\mathrm{a}}$ pessoas, mas somente oposição binária, pessoa $x$ não pessoa, articulada a uma oposição singular $x$ plural. A não oposição de pessoas "[...] corresponde a uma concordância fraca ${ }^{2}$ morfologicamente (ausência de $2^{a}$ pessoa) e semanticamente - possibilidade de interpretar a $3^{\mathrm{a}}$ pessoa do singular como indeterminada." (GALVES, 1993, p.395).

Se historicamente constituiu-se, para o português brasileiro, a imagem de língua de concordância fraca, é, também, na história, ou mais precisamente em documentos do século XVI, que Naro e Scherre (2007) encontraram, no português europeu, casos de não concordância. Ao analisar oito textos medievais, esses pesquisadores registraram mais de 200 ocorrências de formas verbais de terceira pessoa do singular em contextos em que a norma exigiria obrigatoriamente formas plurais de terceira pessoa. Apesar de estarem registrados os casos de não concordância, explicou-se o desvio à norma-padrão pela "maléfica" interferência dos escribas e editores.

Duarte, Kato e Barbosa (2001, p.406) também constataram a não aplicação da regra de concordância no português europeu. As autoras afirmam que: "[...] quanto à concordância com o argumento interno plural ou composto, o default nas receitas portuguesas é usar concordância, mas encontraram-se casos sem concordância."

No vernáculo brasileiro, a concordância verbal é um fenômeno variável e a sistematicidade da variação é explicada, em grande parte, pela saliência fônica da desinência verbal e pela posição do sujeito em relação ao verbo: (i) o aumento da saliência no material fônico na oposição singular/plural ( $3^{a}$ pessoa) implica maiores chances de concordância - bateu/bateram. Em contrapartida, oposições menos salientes resultam em menos marcações de plural - bate/batem; (ii) a posição do sujeito à esquerda do verbo - posição de proeminência de tópico - favorece a ocorrência de variantes explícitas de plural - Os meninos chutaram a bola (SCHERRE, 1994; NARO; SCHERRE, 1999, 2000).

Mas não é só no vernáculo brasileiro que a saliência fônica da desinência verbal afeta positiva e negativamente a norma-padrão. Os resultados da análise

"É fraca a concordância que não contém pessoa, ou contém pessoa com o traço puramente sintático." (GALVES, 1993, p.395). 
da concordância verbal no português arcaico, em um corpus constituído por documentos notariais do noroeste de Portugal e da região de Lisboa mostraram que "[...] as oposições mais salientes não deixaram dúvidas quanto à posição dos notários em estabelecer a diferença entre singular e plural, [mas] o mesmo não se pode afirmar quando se trata de contextos menos salientes." (SOUZA, 2007, p.08).

Apesar de o português europeu não padrão também exibir para a concordância sujeito e verbo alguma variação, as imagens da variedade de além-mar estão vinculadas a uma língua de concordância forte 3 (CARRILHO, 2007; GALVES, 1993, 2001). O predomínio da opção pelo sujeito nulo atesta que o português europeu ainda mantém uma morfologia verbal rica (DUARTE, 1995).

É consensual que a concordância entre o sujeito e o verbo em frases finitas é uma relação fundamental no português europeu e que a variação (excluídos os casos de concordância lógica e as construções com sujeitos complexos ou coordenados $^{4}$ ) está circunscrita a contextos em que o constituinte (sujeito) se encontra em posição pós-verbal, " "...] variação que não enfraquece a uniformidade da relação de concordância." (CARRILHO, 2007, p.02).

Surpreendentemente, em nosso corpus de análise, a variação na regra de concordância no português europeu não está circunscrita apenas a contextos em que o constituinte (sujeito) se encontra em posição pós-verbal. Há casos - ainda que não muito expressivos numericamente, mas não menos importantes - de não aplicação da regra com sujeitos antepostos, resultado que qualitativamente permite afirmar que as estruturas não padrão dessa variedade de língua são sensíveis às mesmas forças linguísticas que caracterizam o português brasileiro.

Os exemplos (1), (2) e (3) ilustram a não concordância com sujeitos antepostos:

\footnotetext{
3 "The intuitive idea is that where there is overt agreement, the subject can be dropped, since the deletion is recoverable" (CHOMSKY, 1982, p.241). Subjaz a essa proposição a ideia de que a morfologia forte ou rica licencia o sujeito nulo: o apagamento é autorizado pela marca de concordância entre o sujeito e o verbo.

4 Para ilustrar os casos de concordância lógica e construções com sujeitos complexos ou coordenados, transcrevem-se exemplos, retirados de Scherre e Naro (2000): "Boa parte dos partos não OCORRE em hospitais." (SCHERRE; NARO, 2000, p.09, grifo do autor), "Mas acho que boa parte de suas reflexões se ADAPTAM aos impasses da imprensa brasileira." (SCHERRE; NARO, 2000, p.09, grifo do autor), "Em apenas

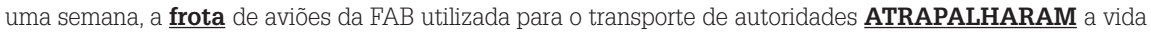
dos ministros do governo Fernando Henrique." (SCHERRE; NARO, 2000, p.17, grifo do autor), "1ㅜㅇ da população ativa do país ESTÁ desempregada." (SCHERRE; NARO, 2000, p.03, grifo do autor), "푸% da população APOIAM a entrada de Erundina no ministério." (SCHERRE; NARO, 2000, p.03, grifo do autor), "Um grupo de artistas ESTAVA sábado à noite no Cine Ricamar." (SCHERRE; NARO, 2000, p.09, grifo do autor); e Scherre (1994) "Um grupo de turistas CHEGAM a uma aldeia de canibais e vão a um restaurante." (SCHERRE, 1994, p.10, grifo do autor), "O crescimento e o dinamismo da economia da Tailândia $\mathbf{S}$ ÃO incompatíveis com a tradição de compra de votos." (SCHERRE, 1994, p.10, grifo do autor), "A atuação da máfia do contrabando e o crescente interesse de comerciantes em descarregar mercadorias em bancas de camelô ESTÁ inflacionando o mercado do asfalto." (SCHERRE, 1994, p.10, grifo do autor).
} 
(1) Ah, havia moinhos, mas isso já era diferente. Quer dizer, a casa era toda de parede, em cima tinha um chapéu, que é onde tinha o velame - só o chapéu! - e tinha umas rodas dentro, que as rodas entrava ${ }^{5}$ dentro dumas calhas de pedra, que tinha dentro e ele por dentro tinha como um cabrestante.

(2) Diz ela: O que é que... tu vê lá se lhe dás algum jeito. E ele riu-se. E ele:Tu queres que eu perca o pão por causa dum soldado? Diz ela: Não perdes nada! tu vai e fazes... E não tenhas medo. (Foi isso).

(3) Depois inventários, dois inventários, porque nós era tudo menor, só ele é que era o mais velho, é que era de maior idade, pronto. Aquilo, meu amigo! E ele tanto que viu ele aí sempre a pedirem dinheiro ao meu pai.

\section{A realização do sujeito na fala do português europeu}

A descrição da realização do sujeito no português europeu conta com uma vasta bibliografia, inscrita, em geral, em uma abordagem eminentemente gerativista. Por essa razão, a interlocução dos nossos resultados fica restrita à pesquisa de Duarte (1995), que, apesar de também adotar os pressupostos gerativistas, usa os procedimentos teórico-metodológicos da Variação e Mudança Linguísticas de linha laboviana.

O corpus no estudo de Duarte. Para compor um quadro que fosse representativo da norma coloquial europeia, na pesquisa de Duarte (1995), foram selecionados 30 informantes distribuídos em três diferentes graus de escolaridade (básico, médio e superior) e duas faixas etárias (de 22 a 33 anos e de 46 a 60 anos). 0 corpus, constituído por transcrições de entrevistas, totalizou 1116 ocorrências: 738 de sujeitos nulos (66\%) e 378 de sujeitos preenchidos (34\%). Resultado que ratifica o português europeu como língua [+] pro-drop.

O corpus do nosso estudo. Pelo fato de a classificação dos dialetos portugueses não ser unânime entre os dialetólogos (CINTRA, 1971), as dez entrevistas ${ }^{6}$, que compuseram o corpus da nossa pesquisa, foram gravadas com falantes portugueses de diferentes regiões, independentemente de serem classificadas como dialetos, subdialetos, co-dialetos, entre outros. Em função das características da constituição do corpus, a localidade é o único fator não estrutural que consta da análise dos dados.

As variantes "categoria vazia" e "pronome", que constituíram nosso envelope de variação, referem-se a sujeitos de referência definida e arbitrária

Este exemplo não consta do cômputo geral dos dados analisados. A transcrição de uma ocorrência em que o verbo não concorda com o SN teve por objetivo mostrar que a variação não se restringe a pronomes.

6 As dez entrevistas selecionadas compõem o Corpus Dialetal para o Estudo da Sintaxe (CORDIAL-SIN), disponibilizado pela Internet no endereço <http://www.clul.ul.pt>. As localidades investigadas foram: Alcochete, Alvor, Arcos, Cabeço de Vide, Camacha, Covo, Figueiró, Outeiro, Ponta Garça e Serpa. 
em sentenças finitas e infinitivas ${ }^{7}$. Estudos que investigaram a realização do sujeito no português brasileiro apresentaram evidências do aparecimento de construções pronominais nominativas para representar sujeitos arbitrários (DUARTE, 1993, 1995, DUARTE; KATO; BARBOSA, 2001; LAPERUTA, 2002). Portanto, ao computarmos em separado sujeitos de referência definida e sujeitos de referência arbitrária, buscou-se observar: (i) se o português europeu, tradicionalmente língua de sujeitos nulos, exibe sujeitos arbitrários preenchidos por pronomes; (ii) se nessa variedade de língua, caso já não licencie o sujeito nulo com tanta intensidade como o faz uma língua tipicamente [+] pro-drop, o preenchimento do sujeito segue a mesma direção do português brasileiro: do definido para o arbitrário.

No total geral, contabilizamos 4398 ocorrências: 2952 (67\%) de sujeitos preenchidos pelo uso de pronome e 1446 (33\%) de sujeitos nulos. Ao observarmos separadamente sujeito de referência definida e sujeito de referência arbitrária, os números que obtivemos foram: 2453 e 1945, respectivamente. Das 2453 ocorrências de sujeito com referência definida, 1728 (70\%) são preenchidos por pronomes e 725 (30\%) são nulos. Com o sujeito de referência arbitrária o percentual de preenchimento também foi expressivo, 63\%.

A comparação entre os nossos resultados e os de Duarte ([2013?]) mostra que o percentual de sujeitos preenchidos é diametralmente oposto ao uso da categoria vazia nessa mesma posição: 66\% de apagamento contra 67\% de preenchimento pelo uso do pronome. Se por um lado, na pesquisa de Duarte ([2013?]), o percentual de sujeitos nulos (66\%) confirma o português europeu como língua [+] pro-drop; por outro lado, nos nossos resultados, os $67 \%$ de sujeitos preenchidos pelo uso do pronome permitem afirmar que essa variedade de língua já não é tipicamente [+] pro-drop.

\section{A concordância verbal e a realização do sujeito na fala do português europeu}

Em nosso corpus de análise, o índice percentual de aplicação da regra de concordância com sujeitos preenchidos e nulos chegou a 87\%. Os resultados da pesquisa de Duarte (1995) também confirmam que o português europeu mantém um paradigma funcionalmente "rico", embora apresente formas homógrafas ${ }^{8}$ para algumas pessoas gramaticais.

\footnotetext{
A inclusão das infinitivas justifica-se pelo fato de a categoria "concordância" poder estar presente nesse tipo de oração e eventualmente permitir a ocorrência de sujeitos lexicais com Caso Nominativo (GONÇALVES, 1994).

Formas iguais para designar diferentes pessoas gramaticais, que pode ser a própria desinência zero (DUARTE, 1995)
} 
Para o português brasileiro, a significativa redução no uso de sujeito nulo está intimamente relacionada à simplificação nos paradigmas flexionais (DUARTE, 1993, 1995); para o português europeu, os resultados, exibidos na Tabela (1), mostram que essa correlação existe, mas não é necessária.

\section{Tabela 1 - Quantificação e porcentagem do cruzamento das variáveis sujeito de referência definida e concordância verbal.}

\begin{tabular}{ccc|c}
\hline Concordância verbal & Sujeito preenchido & Sujeito nulo & Total \\
\hline Concordância & $216(69 \%)$ & $95(31 \%)$ & 311 \\
Não concordância & $40(87 \%)$ & $06(13 \%)$ & 46 \\
\hline Total $^{9}$ & 256 & 101 & 357 \\
\hline
\end{tabular}

Fonte: Elaboração própria.

Embora o percentual de sujeitos preenchidos seja expressivo - quer em estruturas com morfologia distintiva, quer em estruturas com morfologia não distintiva - os números confirmam que a não concordância se associa preferencialmente a sujeitos foneticamente realizados (87\%). Se não se pode explicar o preenchimento dos sujeitos pelo viés da morfologia verbal, também não se pode negar que haja entre eles uma confluência de motivações.

Para exemplificar morfologia distintiva e sujeitos preenchidos e nulos, apresentamos ocorrências computadas em nosso corpus de análise:

(4) Abaixo da ponte de Santar, um moinho com três moinhos de dorna. É por isso que eu sei, que estou aqui. Que eu não, eu não... Eu era sempre azenhas. $\underline{\text { Nós }}$ nascemos na azenha, aqui. Nós não nascemos na azenha; $\underline{\emptyset}$ estamos é na azenha.

(5) E diz ele assim: Tu estás maluco, pá! Então tu não vês que aqui que é um terreno muito mais alto do que é além onde tu estás a dizer que vai dar água para aqui"?! "Não é isso que lhe eu estou a dizer, homem"! "Então o que é que tu estás a dizer.

(6) Os senhores vão-se embora que os senhores, na paz de Deus, de vocês não (cobro) nada. As raparigas assentaram-se ao pé de nós, o pai também, a mãe também, ali comer, comer... Quer dizer, nós enchemos Nós comemos bem!

Na Tabela (2), podemos observar que o sujeito de referência arbitrária também exibe alto índice percentual de aplicação da regra de concordância (83\%). Se por

9 Do total de 2453 sujeitos de referência definida, apenas 357 exibem marcas distintivas - (tu, nós, vós ou eles). 
um lado, a manutenção de um paradigma funcionalmente "rico" não impediu que o português europeu preenchesse a casa do sujeito; por outro lado, o uso do pronome foi afetado positivamente pela não concordância.

\section{Tabela 2 - Quantificação e porcentagem de ocorrências do cruzamento das variáveis sujeito de referência arbitrária e concordância verbal.}

\begin{tabular}{c|c|c|c}
\hline Concordância verbal & Sujeito preenchido & Sujeito nulo & Total \\
\hline Concordância & $845(66 \%)$ & $443(34 \%)$ & 1288 \\
Não concordância & $212(82 \%)$ & $45(18 \%)$ & 257 \\
\hline Total $^{10}$ & 1057 & 488 & 1545 \\
\hline
\end{tabular}

Fonte: Elaboração própria.

Ao constatar que o preenchimento da casa do sujeito é expressivo, quer em estruturas com morfologia distintiva, quer em estruturas com morfologia não distintiva - mais neste caso do que naquele - pode-se concluir que: (i) o português europeu já não é uma língua tipicamente [+] pro-drop; (ii) a aplicação da regra de concordância é um contexto de relativo maior uso do sujeito nulo.

O exemplo (7) ilustra sujeito preenchido e morfologia verbal distintiva e o (8) sujeito preenchido e morfologia não distintiva:

(7) Quando a azeitona está madura, o que se lhe faz é o varejo. Bom, nós vamos ao varejo e as mulheres vão ao apanho. Aqui a palavra para o homem é uma maneira e para a mulher é outra.

(8) E o livro dizia que os homens que haviam de voar mais alto que os passaritos. E quando nós visse estas serras todas cortadas, de estradas e tudo do homem, que o mundo que era um paraíso, que ele que o mundo que durava pouco.

\section{A concordância verbal com a forma pronominal a gente no português brasileiro e europeu}

Quer no português brasileiro, quer no português europeu, a forma pronominal a gente não é mencionada na grande maioria das gramáticas prescritivas. Além da escassez de descrição e das contradições de classificação (pronome pessoal, forma de tratamento, pronome indefinido), essa forma pronominal,

10 Foram 400 ocorrências com pronomes que não exibem marcas de flexão (eu, você, ele/ela, senhor/senhora). 
envolta por dogmas, ainda não é unanimemente aceita como parte da gramática do português padrão. "As escolas censuravam o uso de a gente, a coberto da perspectiva normativa banalizada no bordão que 'agente' é da polícia.» (PEREIRA, 2003, p.05, grifo nosso)

Apesar da resistência à inclusão da forma pronominal a gente no quadro tradicional, os registros de uso datam do século XVIII. O percurso diacrônico dessa forma pronominal inclui não só a multirreferenciação, mas também a perda gradual do traço de número [+] plural. "Embora a subespecificação [possibilidade de o pronome exibir o verbo no singular ou no plural] se faça presente até o século XIX, o uso de a gente apenas no singular ganha terreno ao longo do tempo, firmando-se como uso categórico no nosso século." (LOPES, 2002, p.28, grifo nosso).

Quer no português brasileiro, quer no português europeu, o uso da forma pronominal a gente é muito expressivo (DUARTE, 1993, 1995; DUARTE; KATO; BARBOSA, 2001; CAVALCANTE, S., 2002; PEREIRA, 2003; CARVALHO, 2005). $\mathrm{Na}$ fala do português europeu, registramos para essa forma pronominal (pronome que simboliza uma ruptura com a regularidade da sentença latina - perfeita correspondência entre as pessoas do pronome e pessoas do verbo) três diferentes possibilidades de concordância verbal: $1^{\text {a }}$ pessoa do plural, $3^{\mathrm{a}}$ pessoa do singular e $3^{a}$ pessoa do plural. Nos exemplos (9), (10) e (11) podemos observar as diferentes flexões:

(9) Então ele já deu ordem? Já! Então, olhe, leve os que quiser e vá para lá. Não. Não é preciso levar muitos. Comigo, três. Vão mais dois aí desses. $\underline{\boldsymbol{A} \text { gente vamos }}$ lá fazer aquilo.

(10) Em moleiro e em barroqueiro. E (eu) agora sou camponês $\underline{\boldsymbol{A} \text { gente trabalhava }}$ com umas bestas, a acartar madeira, a acartar enchimento para as estufas. $\underline{\boldsymbol{A}}$ gente trata o barroqueiro é um arreeiro.

(11) É uma linhaça. Tratam linhaça, que é a semente que até diz que é muito bom para deitar em vistas quando estão inflamadas - e que no tempo a gente deitavam. Na nossa casa deitava-se. Se tinha alguma coisa dentro, aquilo no outro dia... $\underline{\boldsymbol{A}}$ gente deitavam um grãozinho daquilo e aquilo limpava a vista.

A variação na concordância verbal com a forma pronominal a gente já foi descrita por pesquisadores portugueses (FARIA, 1997; PEREIRA, 2003), mas acreditamos que a nossa contribuição esteja no fato de termos constatado, na fala de um mesmo informante, o uso das três diferentes possibilidades de concordância sujeito e verbo, conforme se pode observar nos exemplos (12), (13) e (14): 
(12) Selha ou a dorna. Sim senhora. Tanto faz grande como pequena. $\underline{\boldsymbol{A} \text { gente }}$ habituaram se: Ah! Traz-me aquela selha! Traz a selha maior! Traz a selha mais pequena!. (Amós - Ponta Garça)

(13) Quando há pouca uva, a gente deitam numa, por exemplo, desses já - um balseiro grande, seja uma selha pequena, que fazem o mesmo trabalho, não é? Agora se há muita uva para deitar dentro, pois a gente temos outros balseiros que tratam os balseiros - maiores. (Amós - Ponta Garça)

(14) Quando a gente pegam nela, ela larga um mau cheiro. Que a gente fica com as mãos... Largam aquele cheiro. (Amós - Ponta Garça)

No português europeu, a concordância não é sistemática, mas “[...] o uso normativo [também] recomenda a gente com a $3^{\mathrm{a}}$ pessoa verbal, sendo a sua concordância com a $4^{a}$ pessoa considerada como própria da chamada linguagem popular." (NASCIMENTO, 1989, p.486, grifo nosso).

A variação na concordância verbal com a forma pronominal a gente, que encontramos na fala do português europeu, atesta que nessa variedade de língua também há regras variáveis em estruturas não padrão.

\section{A realização do sujeito a gente no português europeu}

Para indeterminar o sujeito, além da reanálise do se apassivador como se impessoal e posteriormente a sua supressão, ou o emprego do paciente como tópico e o verbo indicando a ação na terceira pessoa, sem que o agente seja especificado, o português brasileiro usa formas nominativas expressas ou nulas, já o português europeu mantém a partícula se e, em construções com verbos transitivos, a concordância do verbo com o sujeito passivo (NARO, 1976; NUNES, 1991; DUARTE, 1995).

O uso de formas nominativas como estratégia de indeterminação do sujeito está relacionado “[...] a uma mudança mais geral no português brasileiro - perda do sujeito nulo - mudança que se iniciou com os sujeitos referenciais de primeira e segunda pessoa." (DUARTE; KATO; BARBOSA, 2001, p.405, grifo nosso).

A produtividade de uso da forma pronominal a gente já não é exclusividade do português brasileiro: no português europeu, esse pronome, além de disputar espaço com a partícula se - que já não é a única (talvez nem a principal) estratégia de indeterminação do sujeito - também concorre com o pronome eu (ou, eu e outro(s)) de referência definida. Os resultados da nossa pesquisa, apresentados na Tabela (3), confirmam a inserção dessa forma inovadora. 


\section{Tabela 3 - Quantificação e porcentagem de ocorrências do sujeito a gente de referência definida e arbitrária.}

\begin{tabular}{ccc|c}
\hline Forma pronominal a gente & Sujeito preenchido & Sujeito nulo & Total \\
\hline Referência definida & $83(89 \%)$ & $10(11 \%)$ & 93 \\
Referência arbitrária & $877(84 \%)$ & $164(16 \%)$ & 1041 \\
\hline Total & 960 & 174 & 1134 \\
\hline
\end{tabular}

Fonte: Elaboração própria.

Se, por um lado, a análise da realização do sujeito no português europeu em um corpus de língua falada não nos permite estabelecer uma correlação necessária entre sujeito nulo e caráter forte da flexão verbal; por outro lado, essa correlação fica evidenciada principalmente com a forma pronominal a gente, cuja morfologia verbal apresenta, em algumas localidades do território português, três diferentes flexões: $1^{\mathrm{a}}$ pessoa do plural, $3^{\mathrm{a}}$ pessoa do singular e $3^{\mathrm{a}}$ pessoa do plural.

Pelo fato de a forma pronominal a gente estar vinculada a verbos que exibem morfologia [+] e [-] plural, codificamos o singular como concordância e o plural como não concordância. Essa opção metodológica foi pautada pelo aceite tácito de que, no português europeu e no português brasileiro, o singular é a forma padrão. No nosso corpus de análise, conforme se pode observar na Tabela (4), o sujeito de referência definida registrou $26 \%$ de não aplicação da regra de concordância verbal.

\section{Tabela 4 - Quantificação e porcentagem de ocorrências do cruzamento das variáveis sujeito a gente de referência definida e concordância verbal.}

\begin{tabular}{ccccc}
\hline Concordância verbal & Sujeito preenchido & Sujeito nulo & Total \\
\hline Concordância & $60(87 \%)$ & $09(13 \%)$ & 69 \\
Não concordância & $23(96 \%)$ & $01(4 \%)$ & 24 \\
\hline Total & 83 & 10 & 93 \\
\hline
\end{tabular}

Fonte: Elaboração própria.

Os exemplos de (15) a (18) ilustram sujeitos de referência definida preenchidos pela forma pronominal a gente: 
(15) O meu pai trazia, quando era... Que a gente tosquiavam as ovelhas duas vezes no ano. Duas ou três vezes, parece-me. Não tenho bem a certeza, mas duas era firme. Porque se não se tosquiava as ovelhas a tempo e a hora, elas ficavam tomadas e morriam.

(16) Se há formiga-branca neste Porto Santo! $\underline{\boldsymbol{A} \text { gente }}$ sentia ela roer. $\underline{\boldsymbol{A} \text { gente }}$ sentia elas roer. A esta porta deste lado, a parte esquerda, eu já nem lha podia abrir, porque se eu lha abrisse, ela ia trazer o aro consigo. Porque o aro estava só com aquela casquinha! Quem lha forcejasse para (ela abrir) ou para (ela fechar) /ha fechar\, ela ia vir sempre. Ia desapegar.

(17) Eu já não disse à senhora? Eu gosto muito de coisas antigas. E $\underline{\text { a gente estiveram }}$ fazendo limpeza lá em cima, à casa de meu pai. Tinha ferraduras, tinha de embolar os bois. Papá tinha isso tudo.

(18) Ah! A mais novinha, que é esta, tinha dois anos e meio! Veja lá, tudo pequeno.

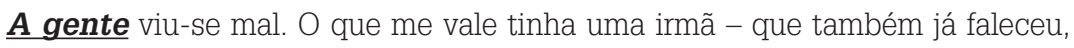
coitada e essa ajudava-me muito. Essa (ele) estava solteira e andava assim a servir sempre (pouco). Trabalhava era de cozinha e assim pelos fidalgos.

Os nossos resultados, apresentados na Tabela (5), confirmam que o uso do singular também foi majoritário com o sujeito de referência arbitrária: 77\% do total geral. Para o português brasileiro, o singular já se tornou a forma tacitamente aceita como regra. O que talvez explique a preferência da forma singular sobre a plural, quer no português europeu, quer no português brasileiro.

\section{Tabela 5 - Quantificação e porcentagem de ocorrências do cruzamento das variáveis concordância verbal e sujeito a gente de referência arbitrária.}

\begin{tabular}{ccc|c}
\hline Concordância verbal & Sujeito preenchido & Sujeito nulo & Total \\
\hline Concordância & $676(84 \%)$ & $124(16 \%)$ & 800 \\
Não concordância & $201(83 \%)$ & $40(17 \%)$ & 241 \\
\hline Total & 877 & 164 & 1041 \\
\hline
\end{tabular}

Fonte: Elaboração própria.

As ocorrências (19), (20) e (21), retiradas do nosso corpus de análise, exemplificam sujeito de referência arbitrária e verbo na $3^{a}$ pessoa do singular:

(19) Joga-se a palha contra o vento. Se o vento está daqui, a gente leva a forquilha a este lado e joga-o para aqui. Porque o bago vai para aquele lado (...) e a palha avoa para a frente. E então tem de se começar: se o vento está deste lado, a gente 
começava a jogar a palha ao ar deste lado, que é para a ir levando sempre para diante, sempre para diante.

(20) A gente tira um enxame - chama aquilo um enxame; ele estava o cortiço cheio de abelhas e a gente vê se elas estão em termos de dar enxame. Bate, bate, bate assim noutro e põe um cortiço a quase sem nada. É como está a senhora Gabriela e o cortiço está ali assim; e a gente põe aquilo no chão, o outro, com a boca encostada um ao outro, e começa a bater no que tem as abelhas: tumba, tumba, tumba.

(21) E aqueles que tem que nunca nada colhe pois estão mais mal. Porque a gente

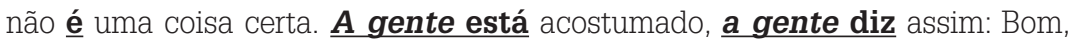
este mês ganhei dez ou doze contos; vou-mos gastar. Mas lá vem outro mês que

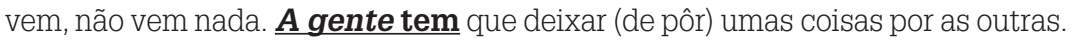

Para observar se a variação na concordância de número e de pessoa também ocorre em estruturas em que os sujeitos são correferentes, cruzamos duas variáveis: sujeitos correferentes $x$ marca de flexão. Nos resultados com sujeitos de referência definida, exibidos na Tabela (6), apenas duas ocorrências não mantiveram o verbo na mesma flexão: na fala do português europeu há alteração do traço de número e de pessoa em orações, cujos sujeitos preenchidos são correferentes.

\section{Tabela 6 - Quantificação e porcentagem de ocorrências do cruzamento das variáveis sujeitos correferentes a gente de referência definida e marcas da flexão verbal.}

\begin{tabular}{c|c|c|c}
\hline Marcas da flexão verbal & $\begin{array}{c}\text { Mesmo sujeito } \\
\text { preenchido }\end{array}$ & Mesmo sujeito nulo & Total \\
\hline Mesma flexão & $05(33 \%)$ & $10(67 \%)$ & 15 \\
Outra flexão & $02(100 \%)$ & - & 02 \\
\hline Total & 07 & 10 & 17 \\
\hline
\end{tabular}

Fonte: Elaboração própria.

No exemplo (22), podemos constatar a manutenção de um mesmo sujeito e o uso de diferentes flexões. Passemos às ocorrências: na primeira delas, o sujeito a gente (da $2^{\mathrm{a}}$ oração) é correferente e exibe o verbo na $1^{\mathrm{a}}$ pessoa do plural - diferentemente da $1^{\mathrm{a}}$ oração, que traz o verbo na $3^{\mathrm{a}}$ pessoa do plural. A segunda ocorrência refere-se ao sujeito a gente da $3^{a}$ oração, que não mantém o verbo na $1^{a}$ pessoa do plural - a concordância volta a ser, assim como na $1^{a}$ oração, com a $3^{\mathrm{a}}$ pessoa do plural. 


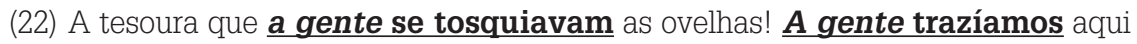
para baixo, depois a gente peavam-nas, as mãos e os pés, para elas estarem quietinhas, a gente pegavam-lhe pela cabeça, começavam pela cabeça, e iam, iam, iam, e iam cortando em toda a volta, e a lã ia enrolando de volta do corpo da ovelha.

Com referência arbitrária, também há variação na desinência de número e de pessoa com sujeitos correferentes e o índice de preenchimento foi sensivelmente mais alto, quando não se mantém a mesma flexão verbal. Mas, surpreendentemente, conforme apresentado na Tabela (7), esse contexto alternou a desinência verbal com sujeitos não realizados foneticamente.

\section{Tabela 7 - Quantificação e porcentagem de ocorrências do cruzamento das variáveis sujeitos correferentes a gente de referência arbitrária e marcas da flexão verbal.}

\begin{tabular}{ccccc}
\hline Marcas da flexão verbal & Mesmo sujeito preenchido & Mesmo sujeito nulo & Total \\
\hline Mesma flexão & $89(37 \%)$ & $149(63 \%)$ & 238 \\
Outra flexão & $16(55 \%)$ & $13(45 \%)$ & 29 \\
\hline Total & 105 & 162 & 267 \\
\hline
\end{tabular}

Fonte: Elaboração própria.

Os exemplos de (23) a (25) exibem a alternância na desinência verbal com sujeitos correferentes não realizados foneticamente:

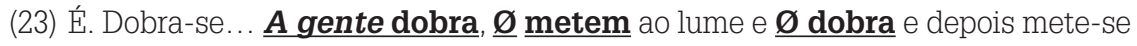
ao jugo para cima. Eu tenho. Eu tenho aí um desses.

(24) Faz-se, (olhe), faz-se o nosso comer, ou o nosso almoço... Quando o porco é morto de manhã, faz-se almoço às vezes de peixe, que é por causa de na parte da tarde ser o sarapatel, da fressura do porco. E quando é na parte da tarde, espera-se que eles abram o porco e (tire) /tirem\ a fressura - como a gente lhe chama - $\underline{\text { Ø já }}$ temos o sangue a escaldar, para esfarelar, para deitar naquele guisado.

(25) Têm um tempero assim diferente; mas, mais ou menos, aquase (imitante). Porque a gente depois vai comer e Ø não dizemos que tem tudo o mesmo gosto. Não. Cada uma coisa tem o seu gosto.

Os resultados com a forma pronominal a gente, qualitativo e quantitativamente expressivos, atestam que a concordância verbal é um fator altamente condicionador na realização ou apagamento do sujeito. O cruzamento das variáveis "correferencialidade e marcas da flexão" mostra que as estruturas com 
sujeitos correferentes (contexto resistente ao preenchimento) apresentam índices não desprezíveis de sujeito lexical, contrariando a expectativa associada a uma língua de sujeito nulo.

\section{Conclusão}

A investigação da realização do sujeito na fala do português europeu evidencia propriedades que refutam a denominação de [+] pro-drop, que essa língua ostenta historicamente, e identifica uma correlação "não necessária" entre preenchimento do sujeito e enfraquecimento da morfologia verbal. Se, por um lado, há expressivos índices percentuais de preenchimento paralelamente a um paradigma verbal funcionalmente rico; por outro lado, há índices percentuais de preenchimento ainda mais expressivos paralelamente à não concordância, notadamente com a forma pronominal a gente.

O alto índice de sujeitos preenchidos pelo uso do pronome e a variação na concordância verbal, especialmente, com a forma pronominal a gente, também usada para indeterminar o sujeito, constituem evidências, pelo menos em relação a esses fenômenos, de que as estruturas não padrão do português europeu são sensíveis às mesmas forças linguísticas que caracterizam o português brasileiro. Fala-se a mesma língua dos dois lados do Atlântico.

CARVALHO, G. A. de. Subject-verb agreement in European Portuguese: variation and subject realization. Alfa, São Paulo, v.57, n.1, p.81-98, 2013.

- ABSTRACT: This paper discusses the relationship between null subject and strong verbal inflection. The analysis of subject realization in a spoken European Portuguese language corpus shows that, although this relationship does exist, it is not necessary: (i) the percentage of realized subjects with sufficiently marked verbal inflection is significant; (ii) lack of subjectverb agreement negatively affects the use of null subject, especially when the pronoun form "a gente" (we) is employed, for it has three different verbal inflections (1 ${ }^{\text {st }}$ person plural, $3^{\text {rd }}$ person singular, and $3^{r d}$ person plural). Besides the substantial percentage of subject realization, there are occurrences - though not so expressive, but not less important - of lack of subject-verb agreement in utterances with subject-verb sentence structures, which contradicts usual variations in European Portuguese.

- KEYWORDS: European Portuguese. Linguistic variation. Null and overt subjects. Verbal agreement.

\section{REFERÊNCIAS}

BOTASSINI, J. O. M. A elipse do sujeito pronominal na linguagem falada no Paraná: uma análise variacionista. 1998. 105f. Dissertação (Mestrado em Linguística) Faculdade de Letras, Universidade do Paraná, Curitiba, 1998. 
BRAVIN DOS SANTOS, A. M. O sujeito anafórico de $3^{a}$ pessoa na fala culta carioca: um estudo em tempo real. 2006. 149f. Tese (Doutorado em Língua Portuguesa) Faculdade de Letras, Universidade Federal do Rio de Janeiro, Rio de Janeiro, 2006. Disponível em: <http://www.letras.ufrj.br/posverna/doutorado/SantosAMB.pdf>. Acesso em: 20 fev. 2007.

CARRILHO, E. Ainda a unidade e diversidade da língua portuguesa: a sintaxe. Disponível em: <http://www.clul.ul.pt/files/ernestina_carrilho/ernestina_ carrilho_2003b.pdf>. Acesso em: 10 jan. 2007.

CARVALHO, G. A. de. A realização do sujeito na fala do araguaiense. 2005. $186 f$. Dissertação (Mestrado em Linguística e Língua Portuguesa) - Faculdade de Ciências e Letras, Universidade Estadual Paulista, Araraquara, 2005.

CAVALCANTE, M. A. da S. O sujeito pronominal em Alagoas e no Rio de Janeiro: um caso de mudança em progresso. 2001. 128f. Tese (Doutorado em Linguística) Faculdade de Letras, Universidade Federal de Alagoas, Maceió, 2001.

CAVALCANTE, S. Formas de indeterminação na imprensa carioca dos séculos XIX e XX. In: ALKMIM, T. M. (Org.). Para a história do português brasileiro: novos estudos. São Paulo: Humanitas, 2002. v.3. p.197-219.

CHOMSKY, N. Some concepts and consequences of the theory of government and binding. Cambridge: MIT Press, 1982.

. Lectures on government and binding. Dordrecht: Foris Publications, 1981.

CINTRA, L. F. L. Nova proposta de classificação dos dialetos galeco-portugueses. Boletim de Filologia, Lisboa, v.22, p.81-116, 1971.

CUNHA, C. F. da. Gramática da língua portuguesa. 7.ed. Rio de Janeiro: Ministério da Educação e Cultura: Fundação Nacional de Material Escolar, 1980.

DUARTE, M. E. L. O sujeito pronominal no português coloquial europeu. [S.l.], [2013?]. Não publicado.

A perda do princípio "Evite pronome" no português brasileiro. 1995. 149f. Tese (Doutorado em Linguística) - Instituto de Estudos da Linguagem, Universidade Estadual de Campinas, Campinas, 1995.

. Do pronome nulo ao pronome pleno: a trajetória do sujeito no português do Brasil. In: ROBERTS, I.; KATO, M. (Org.). Português brasileiro: uma viagem diacrônica. Campinas: Ed. da UNICAMP, 1993. p.107-128.

DUARTE, M. E. L.; KATO, M. A.; BARBOSA, P. Sujeitos indeterminados em PE e PB. In: CONGRESSO INTERNACIONAL DA ABRALIN, 2., 2001, Fortaleza. Boletim da ABRALIN... Fortaleza: Maria Elias, 2001. v.26. p.405-409. 
FARIA, O. S. de. O nosso falar Ilhéu: glossário de termos, provérbios, crenças e outras histórias. Açores: Angra do Heroísmo, 1997.

GALVES. C. C. Ensaios sobre as gramáticas do português. Campinas: Ed. da UNICAMP, 2001.

. O enfraquecimento da concordância no português brasileiro. In: ROBERTS, I.; KATO, M. (Org.). Português Brasileiro: uma viagem diacrônica. Campinas: Ed. da UNICAMP, 1993. p.387-408.

GONÇALVES, M. F. H. de. S. Para uma definição do parâmetro do sujeito nulo. 1994. 242f. Dissertação (Mestrado em Linguística Portuguesa Descritiva) - Faculdade de Letras, Universidade de Lisboa, Lisboa, 1994.

LAPERUTA, M. A realização do sujeito pronominal: um estudo sociolingüístico paramétrico para a cidade de Londrina - Norte do Paraná. 2002. 138f. Dissertação (Mestrado em Linguística e Língua Portuguesa) - Faculdade de Ciências e Letras, Universidade Estadual Paulista, Araraquara, 2002.

LIRA, S. de A. O sujeito pronominal no português falado e escrito. Tha do desterro, Florianópolis, n.20, p.31-43, 1988.

Nominal, pronominal and zero subject in brazilian portuguese. 1982. $227 \mathrm{f}$. Dissertation (Ph.D. in ilinguistics), University of Pennsylvania, 1982.

LOPES, C. R. dos S. De gente para a gente: o século XIX como fase de transição. In: ALKMIM, T. M. (Org.). Para a história do português brasileiro: novos estudos. São Paulo: Humanitas: FLP: USP, 2002. p.25-46.

LOPES, C. R. dos S.; MACHADO, A. C. M. Tradição e inovação: indícios do sincretismo entre segunda e terceira pessoas nas cartas dos avós. In: LOPES, C. R. dos S.

(Org.). Norma brasileira em construção: fatos lingüísticos em cartas pessoais do século XIX. Rio de Janeiro: FAPERJ, 2005. p.45-66.

NARO. A. J. The genesis of the reflexive impersonal in portuguese. Language, New York, v.52, n.4, p.779-810, 1976.

NARO. A. J.; SCHERRE, M. M. P. Garimpo das origens do português brasileiro. São Paulo: Parábola, 2007.

A hierarquização do controle da concordância no português moderno e medieval: o caso de estruturas de sujeito composto. In: GROBE, S.; ZIMMERMANN, K. (Ed.). O português brasileiro: pesquisas e projetos. Frankfurt am Main: TFM, 2000. v.17. p.166-188. 
. Sobre o princípio de saliência na concordância verbal na fala moderna, na escrita antiga e na escrita moderna. In: MOURA, D. (Org.). Os múltiplos usos da língua. Maceió: EDUFAL, 1999. p.26-37.

NASCIMENTO, M. F. B. A gente, um pronome da 4. ${ }^{a}$ pessoa. In: CONGRESSO SOBRE A INVESTIGAÇÃO E ENSINO DO PORTUGUÊS, 1989, Lisboa. Actas... Lisboa: Ministério da Educação/ICALP, 1989. p.480-490.

NUNES, J. Se apassivador e se indeterminador: o percurso diacrônico no português brasileiro. Cadernos de Estudos Linguísticos, Campinas, v.20, p.33-57, 1991.

PEREIRA, S. M. de B. Gramática comparada de a gente: variação no português europeu. 2003. 149f. Dissertação (Mestrado em Gramática Comparada) - Faculdade de Letras da Universidade de Lisboa, Universidade Nova de Lisboa, Lisboa, 2003. SCHERRE, M. M. P. Aspectos da concordância de número no português do Brasil. Revista Internacional de Língua Portuguesa, Lisboa, v.12, p.37-49, 1994.

SOUZA, P. D. dos S. A concordância verbal no português arcaico: um olhar descritivo sobre a documentação notarial. Disponível em: <http://www.inventario. ufba.br>. Acesso em: 19 maio 2007.

Recebido em 30 de setembro de 2011.

Aceito em 24 de novembro de 2012. 